\title{
Associations between remnant lipoprotein cholesterol and central systolic blood pressure in a Chinese community-based population: a cross-sectional study
}

Kaiyin Li ${ }^{1}$, Fangfang Fan ${ }^{1}$, Bo Zheng ${ }^{1}$, Jia Jia ${ }^{1}$, Bo Liu' ${ }^{1}$, Jiahui Liu', Chuyun Chen ${ }^{1}$, Jing Zhou ${ }^{1 *+}$, Yan Zhang ${ }^{1,2^{*}+}$ (D) and Yong Huo ${ }^{1}$

\begin{abstract}
Background: The lipid profile is reportedly related to peripheral blood pressure or pulse wave velocity. However, no studies have investigated the associations between lipid parameters, especially remnant lipoprotein cholesterol (RLP-C), and central systolic blood pressure (CSBP).
\end{abstract}

Methods: This study used baseline data of a community-based cohort in Beijing, China. Participants who had been treated with anti-hypertensive or lipid-lowering agents were excluded. RLP-C is equal to total cholesterol (TC) minus the sum of low-density lipoprotein cholesterol (LDL-C) and high-density lipoprotein cholesterol (HDL-C). An Omron HEM-9000AI device was used to measure non-invasive CSBP. The associations between blood lipid profile and noninvasive CSBP were evaluated using multivariable regression models.

Results: The 5173 included participants were $55.0 \pm 8.5$ years old; $35.7 \%$ (1845) of participants were men. Increased CSBP was significantly associated with increased TC, LDL-C, non-high-density lipoprotein cholesterol (non-HDL-C), triglyceride (TG), and RLP-C but with decreased HDL-C, even after adjusting for possible covariates. When simultaneously entering individual pairs of RLP-C and other blood lipid parameters into the multivariable regression model, RLP-C remained significantly associated with CSBP, even after adjusting for other lipids. Compared with participants who had RLP-C levels in the first quartile (Q1), CSBP for those with RLP-C in Q4 was increased to 4.57 (95\% confidence interval [Cl]: 3.08-6.06) $\mathrm{mmHg}$ after adjusting for LDL-C, 4.50 (95\%Cl: $2.98-6.02) \mathrm{mmHg}$ after adjusting for TC, 3.91 (95\%Cl: 1.92-5.89) mmHg after adjusting for TG, 5.15 (95\%Cl: 3.67-6.63) mmHg after adjusting for HDL-C, and 4.10 (95\%Cl: 2.36-5.84) mmHg after adjusting for non-HDL-C.

Conclusions: Increased blood RLP-C level was significantly associated with higher CSBP in a Chinese population, independently of other lipids, which indicates its importance in individual cardiovascular risk assessment.

Keywords: Lipids, Remnant lipoprotein cholesterol, Non-high-density lipoprotein cholesterol, Triglyceride, Cholesterol, Low-density lipoprotein cholesterol, Non-invasive central systolic blood pressure, Arterial stiffness

\footnotetext{
*Correspondence: zhoujing123@yahoo.com; drzhy1108@163.com

${ }^{\dagger}$ Jing Zhou and Yan Zhang contributed equally to this work.

'Department of Cardiology, Peking University First Hospital, No. 8 Xishiku Street, Xicheng District, Beijing 100034, China

Full list of author information is available at the end of the article
}

C C The Author(s). 2021 Open Access This article is licensed under a Creative Commons Attribution 4.0 International License, which permits use, sharing, adaptation, distribution and reproduction in any medium or format, as long as you give appropriate credit to the original author(s) and the source, provide a link to the Creative Commons licence, and indicate if changes were made. The images or other third party material in this article are included in the article's Creative Commons licence, unless indicated otherwise in a credit line to the material. If material is not included in the article's Creative Commons licence and your intended use is not permitted by statutory regulation or exceeds the permitted use, you will need to obtain permission directly from the copyright holder. To view a copy of this licence, visit http://creativecommons.org/licenses/by/4.0/ The Creative Commons Public Domain Dedication waiver (http://creativecommons.org/publicdomain/zero/1.0/) applies to the data made available in this article, unless otherwise stated in a credit line to the data. 


\section{Background}

Hypertension accounts for the largest proportion of the global disease burden and mortality in recent years [1]. In 2019, elevated systolic blood pressure (SBP) led to approximately 10.8 million deaths and the highest percentage of disability-adjusted life-years [2]. Hypertension is currently defined according to the peripheral blood pressure; however, pulse wave analysis (PWA) has enabled reproducible and non-invasive measurement of central hemodynamics. Numerous clinical studies have indicated that non-invasive central systolic blood pressure (cSBP) measurement may improve risk stratification for cardiovascular diseases owing to its stronger association with hypertension-mediated organ damage [3-7].

Previous studies have identified an association between blood lipids and blood pressure, although most such studies have focused on the relationships between hypercholesterolemia or hypertriglyceridemia and peripheral blood pressure [8-11]. Additionally, patients with increased remnant lipoprotein cholesterol (RLP-C) levels are more likely to develop incident cardiovascular diseases [12-14]. A 10-year longitudinal study in Japan showed associations between higher plasma RLP-C and incident hypertension [15]. To the best of our knowledge, the relationship between RLP-C and central blood pressure remains unknown. Hence, this retrospective study was conducted to investigate the associations between non-invasive cSBP and lipid profile levels, especially RLP-C.

\section{Methods}

\section{Study design}

This retrospective study used baseline data of a Beijing community-based cohort in China [16]. Among the initial 9540 participants recruited via phone calls or recruitment posters between December 2011 and April 2012, 8062 participants (84.5\%) had effective data of cSBP and RLP-C at baseline. Those participants treated with anti-hypertensive agents $(n=2630)$ and/or lipidlowering agents $(n=952)$ were excluded owing to therapeutic effects on cSBP and blood lipids of these drugs. Finally, 5173 eligible participants were included in the analysis.

\section{Data collection}

Trained research staff collected data by standards, including information on lifestyle, history of diseases and medications, and physical examination. Smoking status, drinking status, hypertension, and diabetes mellitus (DM) have been defined previously [17]. Calculations of estimated glomerular filtration rate (eGFR) and body mass index (BMI) were according to those in a previous publication [18].
After an overnight fast, blood samples were obtained from each participant via forearm venipuncture. Serum glucose, lipid, and creatinine levels were tested using previously published methods [19]. Non-high-density lipoprotein cholesterol (non-HDL-C) was calculated as subtraction of the high-density lipoprotein cholesterol (HDL-C) from the total cholesterol (TC), while the RLP$\mathrm{C}$ was defined as TC minus the sum of low-density lipoprotein cholesterol (LDL-C) and HDL-C.

Before central blood pressure measurement, all participants were required to sit quietly for $5 \mathrm{~min}$. Noninvasive $\mathrm{CSBP}$ was measured using the validated HEM9000AI device (Omron Healthcare, Kyoto, Japan) [2024]. Each participant underwent simultaneous measurement of left radial applanation tonometry and right brachial cuff oscillometric pressure. Radial waveforms were analyzed to obtain the peripheral systolic pressure peaks, and were then calibrated using the measured brachial blood pressure. A linear regression model with the late peak of the peripheral systolic pressure was used to calculate the non-invasive cSBP. This measurement was not repeated due to the tight research schedule.

\section{Statistical analysis}

Mean \pm standard deviation was used to describe continuous variables with a normal distribution, and differences were determined with one-way analysis of variance. Median (interquartile range) was used to describe nonnormally distributed variables, and differences were determined using the Kruskal-Wallis rank test. Number (\%) was used to describe dichotomous variables, and differences were determined using the chi-square test.

Relationships between lipid parameters and cSBP level were examined with generalized additive models using a spline smoothing function. Associations between cSBP and different blood lipid parameters (as continuous variables and quartiles [Q]) were investigated using univariable and multivariable regression models. Age, sex, BMI, eGFR, smoking and drinking status, DM, antidiabetic drug use, myocardial infarction and stroke history were adjusted in multivariable regression analyses. Furthermore, independent associations of RLP-C with CSBP, adjusted for other lipid parameters, were determined by simultaneously entering the pairs of RLP-C and other lipid parameters into the multivariable regression models one at a time. With regard to possible collinearity, the variance inflation factor (VIF) was calculated for the included variables in each multivariable regression model. Empower(R) (www.empowerstats.com, X\&Y Solutions, Inc., Boston, MA, USA) and R (http://www.R-project. org) were used for data analyses, and two-sided $P$ values $<0.05$ were regarded as statistically significant. 


\section{Results}

\section{Baseline characteristics of enrolled participants}

Table 1 summarizes the characteristics of enrolled participants according to quartiles of RLP-C. The 5173 included participants were $55.0 \pm 8.5$ years old, and $35.7 \%$ (1845) were men. Participants with a higher RLP-C level had increased levels of TC, triglyceride (TG), LDL-C, and non-HDL-C, as well as $\mathrm{CSBP}(P<0.001)$. Despite no intergroup difference in the percentage of myocardial infarction or stroke history, participants with a higher RLP-C level tended to be older, male, more likely to smoke and drink, and to have higher BMI, worse renal function, a higher ratio of DM, hypertension $(P<0.001)$ and antidiabetic medication use $(P=0.013)$.

\section{Associations of RLP-C and other lipid profiles with CSBP, considered individually}

The smoothing curves of cSBP by lipid parameter after adjusting for possible covariates are shown in Fig. 1 . The smoothing curves showed a positive linear association between most lipid parameters and cSBP, except that a negative linear association with the HDL-C level and a non-linear trend with RLP-C level were observed.
Associations between the blood lipid profile and cSBP are summarized in Table 2. In the univariable analyses, cSBP showed a graded positive relationship with RLP-C, TC, TG, LDL-C, and non-HDL-C levels, but a graded negative relationship with the HDL-C level $(P<0.001)$. In the adjusted multivariable analyses, higher cSBP was significantly associated with increases in TC, TG, LDL$\mathrm{C}$, RLP-C, and non-HDL-C levels but decreased HDL-C level.

\section{Associations of RLP-C and other lipid profiles with CSBP, considered simultaneously}

The VIF calculated for the included variables in each multivariable regression model did not show any collinearity (Supplementary materials). Table 3 shows the relationship of RLP-C level and other blood lipid parameters with non-invasive cSBP, with simultaneous entry of RLP-C and other lipid in pairs into the multivariable regression models, after adjusting for covariates. Compared with participants who had RLP-C in Q1, the cSBP for those with RLP-C in Q4 was increased to 4.57 (95\% confidence interval [CI]: 3.08-6.06) $\mathrm{mmHg}$ after adjusting for LDL-C, 4.50 (95\%CI: 2.98-6.02) $\mathrm{mmHg}$ after

Table 1 Baseline characteristics of all participants by RLP-C quartile

\begin{tabular}{|c|c|c|c|c|c|c|}
\hline \multirow[t]{2}{*}{ Variables } & \multirow[t]{2}{*}{ Total } & \multicolumn{4}{|c|}{ RLP-C, mmol/L } & \multirow{2}{*}{$\begin{array}{l}P \\
\text { Value }\end{array}$} \\
\hline & & Q1 (<0.39) & $\mathrm{Q} 2(0.39-<0.54)$ & Q3 $(0.54-<0.73)$ & $\mathrm{Q} 4(\geq 0.73)$ & \\
\hline$n$ & 5173 & 1269 & 1283 & 1318 & 1303 & \\
\hline Age, y & $55.0 \pm 8.5$ & $54.2 \pm 8.8$ & $55.3 \pm 9.1$ & $55.5 \pm 8.2$ & $55.0 \pm 7.9$ & $<0.001$ \\
\hline Male, n (\%) & 1845 (35.7\%) & $365(28.8 \%)$ & $444(34.6 \%)$ & $476(36.1 \%)$ & $560(43.0 \%)$ & $<0.001$ \\
\hline BMI, $\mathrm{kg} / \mathrm{m}^{2}$ & $25.5 \pm 3.3$ & $24.0 \pm 3.0$ & $25.3 \pm 3.2$ & $26.1 \pm 3.2$ & $26.7 \pm 3.1$ & $<0.001$ \\
\hline $\mathrm{eGFR}, \mathrm{mL} / \mathrm{min} \cdot 1.73 \mathrm{~m}^{2}$ & $96.8 \pm 12.0$ & $98.7 \pm 11.4$ & $96.9 \pm 11.9$ & $96.1 \pm 11.9$ & $95.4 \pm 12.5$ & $<0.001$ \\
\hline $\mathrm{cSBP}, \mathrm{mmHg}$ & $129.7 \pm 17.3$ & $126.1 \pm 16.8$ & $129.0 \pm 17.3$ & $130.2 \pm 16.8$ & $133.2 \pm 17.4$ & $<0.001$ \\
\hline $\mathrm{TC}, \mathrm{mmol} / \mathrm{L}$ & $5.4 \pm 1.0$ & $4.8 \pm 0.8$ & $5.1 \pm 0.8$ & $5.5 \pm 0.9$ & $6.0 \pm 1.1$ & $<0.001$ \\
\hline $\mathrm{TG}, \mathrm{mmol} / \mathrm{L}$ & $1.2(0.9-1.8)$ & $0.8(0.6-0.9)$ & $1.1(0.9-1.3)$ & $1.4(1.2-1.7)$ & $2.3(1.8-3.1)$ & $<0.001$ \\
\hline $\mathrm{HDL}-\mathrm{C}, \mathrm{mmol} / \mathrm{L}$ & $1.5 \pm 0.4$ & $1.8 \pm 0.4$ & $1.5 \pm 0.3$ & $1.4 \pm 0.3$ & $1.2 \pm 0.3$ & $<0.001$ \\
\hline LDL-C, mmol/L & $3.3 \pm 0.8$ & $2.7 \pm 0.6$ & $3.2 \pm 0.6$ & $3.5 \pm 0.7$ & $3.7 \pm 1.0$ & $<0.001$ \\
\hline RLP-C, mmol/L & $0.5(0.4-0.7)$ & $0.3(0.2-0.4)$ & $0.5(0.4-0.5)$ & $0.6(0.6-0.7)$ & $0.9(0.8-1.1)$ & $<0.001$ \\
\hline Non-HDL-C, mmol/L & $3.9 \pm 1.0$ & $3.0 \pm 0.6$ & $3.6 \pm 0.6$ & $4.1 \pm 0.7$ & $4.8 \pm 1.0$ & $<0.001$ \\
\hline Smoking, n (\%) & $1038(20.1 \%)$ & $163(12.8 \%)$ & $219(17.1 \%)$ & 275 (20.9\%) & 381 (29.2\%) & $<0.001$ \\
\hline Drinking, n (\%) & $1255(24.3 \%)$ & 250 (19.7\%) & 299 (23.3\%) & $317(24.1 \%)$ & 389 (29.9\%) & $<0.001$ \\
\hline \multicolumn{7}{|c|}{ Prevalence of cardiovascular disease, n (\%) } \\
\hline Diabetes mellitus & $953(18.4 \%)$ & $159(12.5 \%)$ & $208(16.2 \%)$ & $253(19.2 \%)$ & $333(25.6 \%)$ & $<0.001$ \\
\hline Self-reported Myocardial Infarction & $21(0.4 \%)$ & $0(0.0 \%)$ & $7(0.6 \%)$ & $7(0.5 \%)$ & $7(0.5 \%)$ & 0.077 \\
\hline Self-reported Stroke history & $97(1.9 \%)$ & $21(1.7 \%)$ & $30(2.3 \%)$ & $28(2.1 \%)$ & $18(1.4 \%)$ & 0.261 \\
\hline Hypertension & $1342(25.9 \%)$ & $237(18.7 \%)$ & $311(24.2 \%)$ & $355(26.9 \%)$ & $439(33.7 \%)$ & $<0.001$ \\
\hline Antidiabetic medication use & $325(6.3 \%)$ & $60(4.7 \%)$ & $76(5.9 \%)$ & $88(6.7 \%)$ & $101(7.8 \%)$ & 0.013 \\
\hline
\end{tabular}

Data are presented as mean \pm standard deviation for normally distributed continuous variables, median (interquartile range) for non-normally distributed continuous variables, and number (percentage) for dichotomous variables

Abbreviations: $B M I$ body mass index, eGFR estimated glomerular filtration rate, $C S B P$ central systolic blood pressure, $T C$ total cholesterol, $T G$ triglyceride, $H D L-C$ high-density lipoprotein cholesterol, $L D L-C$ low-density lipoprotein cholesterol, $R L P-C$ remnant lipoprotein cholesterol, non- $H D L-C$ non-high-density lipoprotein cholesterol 

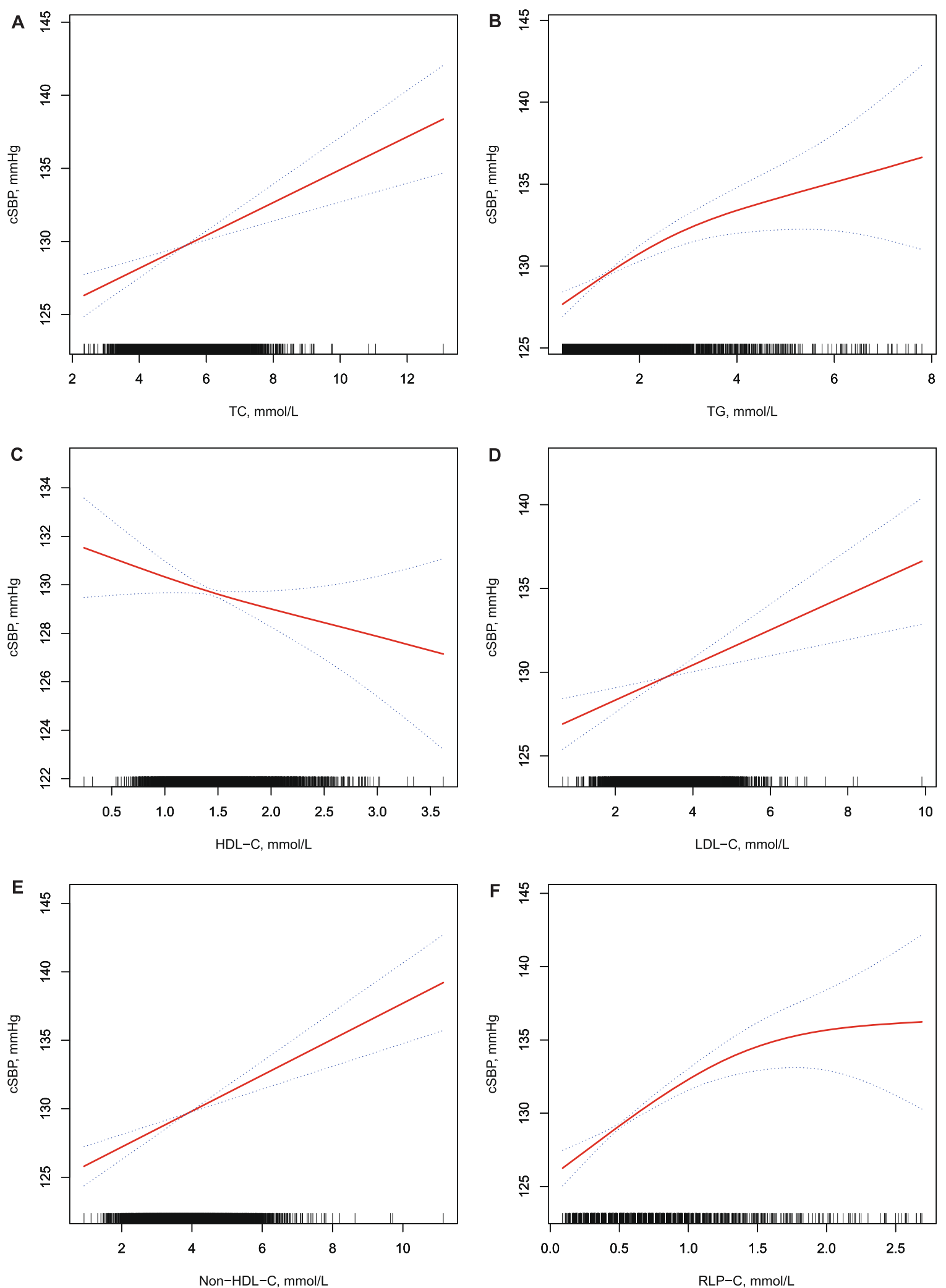

Fig. 1 (See legend on next page.) 
(See figure on previous page.)

Fig. 1 Smoothing curve of cSBP by lipid parameter. Adjusted for sex, age, body mass index, estimated glomerular filtration rate, smoking, alcohol use, diabetes mellitus, antidiabetic drug use, myocardial infarction and stroke. A: Association between TC and cSBP. B: Association between TG and CSBP. C: Association between HDL-C and CSBP. D: Association between LDL-C and CSBP. E: Association between non-HDL-C and CSBP. F: Association between RLP-C and CSBP. cSBP: central systolic blood pressure; TC: total cholesterol; TG: triglyceride; HDL-C: high-density lipoprotein cholesterol; LDL-C: low-density lipoprotein cholesterol; non-HDL-C: non-high-density lipoprotein cholesterol; RLP-C: remnant

lipoprotein cholesterol

adjusting for TC, 3.91 (95\%CI: 1.92-5.89) $\mathrm{mmHg}$ after adjusting for TG, 5.15 (95\%CI: $3.67-6.63) \mathrm{mmHg}$ after adjusting for HDL-C, and 4.10 (95\%CI: 2.36-5.84) $\mathrm{mmHg}$ after adjusting for non-HDL-C. The other lipid parameters were not significantly associated with cSBP after adjusting for RLP-C.

\section{Discussion}

The present study shows associations between cSBP and blood lipid profiles, especially RLP-C, in a communitydwelling Chinese population. In further analyses by simultaneously entering RLP-C level and other lipid parameters in pairs, the RLP-C level showed a stronger association with non-invasive cSBP.

Although different physiological indices, blood pressure and lipid profiles have overlapping processes owing to common cardiovascular risk factors and complications. Both hypertriglyceridemia and hypercholesterolemia are associated with higher peripheral blood pressure, as reported in previous cross-sectional studies [8-11]. A cohort study further showed that adolescents with a higher TG to HDL-C ratio had a higher risk of developing adult hypertension in a 20-year follow-up [25]; similar results were also observed in another prospective cohort study among pregnant women [26]. Mechanisms such as endothelial cell dysfunction, neuroendocrine system activation, increased salt sensitivity and reduced sodium clearance by nephrons, and higher L-type calcium channel activities in the smooth myofibrils contributed to the relationship [9, 27-33]. However, previous studies focused on peripheral blood pressure, although central blood pressure has been more strongly associated with cardiovascular outcome and hypertension-mediated organ damage [3-7].

Arterial stiffness can be evaluated non-invasively using two-dimensional imaging techniques, pulse wave velocity (PWV), cardio-ankle vascular index (CAVI), and PWA, although carotid-femoral PWV is currently more reliable [34-36]. Associations between TG levels and arterial stiffness have been reported, using all measurements of the CAVI [37], brachial-ankle PWV [38], and carotidfemoral PWV [39]. Regarding cholesterol, aortic stiffness has been positively associated with TC, LDL-C, and non-HDL-C levels, and negatively associated with HDLC level [8, 40-42]. Moreover, large artery stiffness and blood pressure control are improved with statin therapy in patients with hypertension [43], independently of changes in the LDL-C level [44]. The findings of the present cross-sectional study suggested that the blood lipid profile is associated with non-invasive cSBP, and this association might be explained by vascular impairment. Compared with PWV, central blood pressure is more than a tool to measure aortic stiffness; it is associated with a more complex set of determinants, including the physical properties of systemic arteries, PWV, the travel time of a forward wave and its reflection, and the distance to the major reflecting site of a pulse wave [45]. Relationships of these determinants and lipids have been discussed previously. Another cross-sectional study used PWA to show associations between the LDL-C level and wave reflection [46]. Hence, cSBP and PWV are both associated with the lipid profile owing to their shared determinant of aortic stiffness, whereas other determinants of cSBP may enhance this association.

Notably, RLP-C was more strongly associated with cSBP than the other lipid parameters analyzed in the present study, possibly because of its physiological characteristics. RLP-C is defined as the cholesterol content in TG-rich lipoproteins (TRLs), namely intermediatedensity lipoprotein (IDL), very low-density lipoprotein (VLDL), and chylomicron remnants [47-49]. As TG contents are gradually degraded by lipoprotein lipase in the bloodstream, the cholesterol in RLP-C could also be involved in atherosclerosis plaque formation and subsequent cardiovascular events, and it has been recognized as more atherogenic and proinflammatory than the cholesterol in LDL-C [48-52]. A recent study indicated associations of plasma TGs and relatively small-sized LDL particles with the carotid-femoral PWV, despite no significant associations between VLDL/large IDL subclasses (the main carriers of TG in the blood) and the carotidfemoral PWV [53]. This raises the possibility that the TG content in TRLs may indirectly influence this process, considering greater small dense LDL generation in the presence of high VLDL-TG levels [54]. Another study conducted in Japan also linked higher serum RLP$\mathrm{C}$ levels with increased intima-media thickness-defined carotid atherosclerosis and CAVI-defined aortic atherosclerosis [55]. However, an updated analysis of the Copenhagen General Population Study suggests that the cholesterol content in VLDL, but not the TG content, is the main contributor to atherosclerotic disease [56]. 
Table 2 Multivariable adjusted change in CSBP by quartiles of blood lipids, considered individually

\begin{tabular}{|c|c|c|}
\hline Variable & $\begin{array}{l}\text { Change in cSBP, mmHg } \\
(95 \% \mathrm{Cl})\end{array}$ & $P$ value \\
\hline \multicolumn{3}{|l|}{$\mathrm{TC}, \mathrm{mmol} / \mathrm{L}$} \\
\hline Continuous, per $1 \mathrm{mmol} / \mathrm{L}$ & $1.20(0.73-1.67)$ & $<0.001$ \\
\hline \multicolumn{3}{|l|}{ Quartiles } \\
\hline Q1: $<4.70$ & Ref. & \\
\hline Q2: $4.70-<5.28$ & $0.72(-0.57-2.00)$ & 0.274 \\
\hline Q3: 5.28-< 5.95 & $1.99(0.71-3.28)$ & 0.002 \\
\hline Q4: $\geq 5.95$ & $2.58(1.28-3.88)$ & $<0.001$ \\
\hline \multicolumn{3}{|l|}{$\mathrm{TG}, \mathrm{mmol} / \mathrm{L}$} \\
\hline Continuous, per $1 \mathrm{mmol} / \mathrm{L}$ & $0.84(0.49-1.19)$ & $<0.001$ \\
\hline \multicolumn{3}{|l|}{ Quartiles } \\
\hline Q1: $<0.87$ & Ref. & \\
\hline Q2: $0.87-<1.24$ & $1.51(0.23-2.80)$ & 0.021 \\
\hline Q3: $1.24-<1.79$ & $2.30(0.98-3.61)$ & $<0.001$ \\
\hline Q4: $\geq 1.79$ & $4.22(2.87-5.57)$ & $<0.001$ \\
\hline \multicolumn{3}{|l|}{$\mathrm{HDL}-\mathrm{C}, \mathrm{mmol} / \mathrm{L}$} \\
\hline Continuous, per $1 \mathrm{mmol} / \mathrm{L}$ & $-1.43(-2.76--0.10)$ & 0.035 \\
\hline \multicolumn{3}{|l|}{ Quartiles } \\
\hline Q1: $<1.19$ & Ref. & \\
\hline Q2: 1.19-<1.42 & $-0.74(-2.05-0.57)$ & 0.268 \\
\hline Q3: $1.42-<1.68$ & $-1.00(-2.36-0.36)$ & 0.151 \\
\hline Q4: $\geq 1.68$ & $-1.60(-3.03--0.17)$ & 0.028 \\
\hline \multicolumn{3}{|l|}{ LDL-C, mmol/L } \\
\hline Continuous, per $1 \mathrm{mmol} / \mathrm{L}$ & $1.00(0.44-1.56)$ & $<0.001$ \\
\hline \multicolumn{3}{|l|}{ Quartiles } \\
\hline Q1: $<2.73$ & Ref. & \\
\hline Q2: $2.73-<3.24$ & $1.40(0.12-2.68)$ & 0.032 \\
\hline Q3: $3.24-<3.78$ & $1.35(0.06-2.64)$ & 0.041 \\
\hline Q4: $\geq 3.78$ & $2.63(1.34-3.93)$ & $<0.001$ \\
\hline \multicolumn{3}{|l|}{ Non-HDL-C, mmol/L } \\
\hline Continuous, per $1 \mathrm{mmol} / \mathrm{L}$ & $1.38(0.91-1.85)$ & $<0.001$ \\
\hline \multicolumn{3}{|l|}{ Quartiles } \\
\hline Q1: $<3.22$ & Ref. & \\
\hline Q2: $3.22-<3.83$ & $2.33(1.05-3.60)$ & $<0.001$ \\
\hline Q3: $3.83-<4.49$ & $2.14(0.85-3.43)$ & 0.001 \\
\hline Q4: $\geq 4.49$ & $3.88(2.57-5.18)$ & $<0.001$ \\
\hline \multicolumn{3}{|l|}{ RLP-C, mmol/L } \\
\hline Continuous, per $1 \mathrm{mmol} / \mathrm{L}$ & $3.94(2.82-5.07)$ & $<0.001$ \\
\hline \multicolumn{3}{|l|}{ Quartiles } \\
\hline Q1: $<0.39$ & Ref. & \\
\hline Q2: $0.39-<0.54$ & $1.62(0.33-2.91)$ & 0.014 \\
\hline Q3: $0.54-<0.73$ & $2.19(0.88-3.50)$ & 0.001 \\
\hline Q4: $\geq 0.73$ & $4.88(3.53-6.23)$ & $<0.001$ \\
\hline
\end{tabular}

Model adjusted for age, sex, body mass index, estimated glomerular filtration rate, smoking status, drinking status, diabetes mellitus, antidiabetic drug use, history of myocardial infarction and history of stroke

Abbreviations: TC total cholesterol, TG triglyceride, $H D L-C$ high-density lipoprotein cholesterol, LDL-C low-density lipoprotein cholesterol, non-HDL-C non-highdensity lipoprotein cholesterol, RLP-C remnant lipoprotein cholesterol, CSBP central systolic blood pressure
Some studies have focused on the influences of lipid-lowering agents on blood pressure. Statins could substantially reduce peripheral blood pressure (1 to 3 $\mathrm{mmHg})[57,58]$, improve arterial stiffness, and reduce central aortic pressure [59], despite the negative effects of atorvastatin on central hemodynamic parameters identified in the Conduit Artery Function Evaluation-Lipid-Lowering Arm study [60]. Considering the high comorbidity of hypertension and dyslipidemia possibly mediated by adiposity [61], the exact relationship between blood pressure and lipids should be investigated. A recent study showed that statin therapy could enhance blood pressure control in patients with hypertension, independently of the intensity of antihypertensive agents [62]. A mediation analysis also showed that LDL-C reduction after statin treatment is associated with better central blood pressure control [63]. The exact action of lipid-lowing agents on central blood pressure remains unknown, but clinicians should consider performing comprehensive measurement of central blood pressure and lipids profile in individuals with hypertension or dyslipidemia. To uncover the natural relationship of RLP-C with cSBP, participants taking lipid-lowing agents or antihypertensive medications were excluded in this study. Considering that these treated participants may have higher values of lipids or CSBP, analyses after including them were also performed, and the main findings were not substantially changed.

\section{Study strengths and limitations}

This study demonstrated the association between RLP-C and cSBP for the first time, which strengthens the association between blood lipid levels and vascular health from the viewpoint of cSBP. Among the analyzed lipid parameters, RLP-C showed the strongest association with cSBP, offering a novel research direction.

This study also has several limitations. First, central diastolic pressure and pulse pressure were not discussed because the Omron devices used in this study do not measure central diastolic pressure. Second, the enrolled participants were from one site; thus, generalizability of the findings to other populations is unclear. Third, other measures of central arterial stiffness, such as carotid-femoral PWV, were not available in this study. Fourth, despite finding no collinearity in the VIF calculations, the effects of RLP-C on cSBP might not be independent of other lipids because RLP-C has a linear relationship with other lipid fractions. Thus, routine lipid fraction tests and RLP-C assessment should be conducted simultaneously in both scientific research and clinical practice. Last, causality between RLP-C and CSBP cannot be judged because 
Table 3 Multivariable adjusted change in CSBP by quartiles of RLP-C and other lipid parameters, considered simultaneously

\begin{tabular}{|c|c|c|c|c|c|}
\hline Models & $\begin{array}{l}\text { Change in CSBP, } \mathrm{mmHg} \\
(95 \% \mathrm{Cl})\end{array}$ & $P$ value & & $\begin{array}{l}\text { Change in cSBP, } \mathrm{mmHg} \\
(95 \% \mathrm{Cl})\end{array}$ & $P$ valu \\
\hline \multicolumn{6}{|l|}{$\overline{\text { Model I } I^{\dagger}}$} \\
\hline $\mathrm{RLP}-\mathrm{C}, \mathrm{mmol} / \mathrm{L}$ & & & $\mathrm{LDL}-\mathrm{C}, \mathrm{mmol} / \mathrm{L}$ & & \\
\hline Q1: $<0.39$ & Ref. & & Q1: $<2.73$ & Ref. & \\
\hline Q2: $0.39-<0.54$ & $1.43(0.10-2.77)$ & 0.035 & Q2: $2.73-<3.24$ & $0.97(-0.33-2.27)$ & 0.143 \\
\hline Q3: $0.54-<0.73$ & $1.89(0.48-3.31)$ & 0.009 & Q3: $3.24-<3.78$ & $0.43(-0.92-1.79)$ & 0.529 \\
\hline Q4: $\geq 0.73$ & $4.57(3.08-6.06)$ & $<0.001$ & Q4: $\geq 3.78$ & $0.93(-0.50-2.37)$ & 0.202 \\
\hline
\end{tabular}

Model II

RLP-C, mmol/L

Q1: $<0.39 \quad$ Ref.

Q2: $0.39-<0.54$

$1.47(0.15-2.78)$

0.029

Q1 : $<4.70$

Q3: $0.54-<0.73$

$1.90(0.51-3.29)$

0.007

Q2: 4.70-<5.28

Ref.

Q4: $\geq 0.73$

$4.50(2.98-6.02)$

$<0.001$

Q3: $5.28-<5.95$

$0.14(-1.16-1.44)$

0.832

Q4: $\geq 5.95$

$0.92(-0.42-2.26)$

0.178

Model III

RLP-C, mmol/L

Ref.

Q1: < 0.39

$1.22(-0.17-2.62)$

0.087

$\mathrm{TG}, \mathrm{mmol} / \mathrm{L}$

Q2: 0.39-<0.54

$1.53(-0.07-3.13)$

0.061

Q2: $0.87-<1.24$

$0.66(-0.80-2.12)$

0.374

Q3: $0.54-<0.73$

3.91 (1.92-5.89)

$<0.001$

Q3: $1.24-<1.79$

Q4: $\geq 1.79$

Q4: $\geq 0.73$

Model IV ${ }^{\dagger}$

RLP-C, mmol/L

Q1: $<0.39$

Ref.

Q2: 0.39-<0.54

$1.72(0.40-3.03)$

0.010

Q1: < 1.19

Ref.

$0.09(-1.24-1.42)$

0.895

Q3: $0.54-<0.73$

$2.36(0.99-3.73)$

$<0.001$

Q3: $1.42-<1.68$

$0.52(-0.90-1.94)$

0.474

Q4: $\geq 0.73$

$5.15(3.67-6.63)$

$<0.001$

Q4: $\geq 1.68$

$0.59(-0.97-2.15)$

Model $\mathrm{V}^{\dagger}$

RLP-C, mmol/L

Q1: $<0.39$

Ref.

Q2: 0.39-<0.54

$1.15(-0.23-2.53)$

0.104

Non-HDL-C, mmol/L

Q3: $0.54-<0.73$

$1.54(-0.00-3.08)$

0.050

Q1: $<3.22$

Ref.

Q2: $3.22-<3.83$

$1.67(0.31-3.03)$

0.016

Q4: $\geq 0.73$

$4.10(2.36-5.84)$

$<0.001$

Q3: $3.83-<4.49$

$0.79(-0.70-2.28)$

0.300

Q4: $\geq 4.49$

$1.52(-0.16-3.20)$

0.077

${ }^{\dagger} \mathrm{RLP}-\mathrm{C}$ and other blood lipid parameters were simultaneously entered into the multivariable regression model

Model adjusted for age, sex, body mass index, estimated glomerular filtration rate, smoking status, drinking status, diabetes mellitus, antidiabetic drug use, history of myocardial infarction and history of stroke

Abbreviations: CSBP central systolic blood pressure, RLP-C remnant lipoprotein cholesterol, $L D L-C$ low-density lipoprotein cholesterol, $T C$ total cholesterol, $T G$ triglyceride, $H D L-C$ high-density lipoprotein cholesterol, non-HDL-C non-high-density lipoprotein cholesterol

of the characteristics of a cross-sectional study; additional studies are warranted to determine whether a causal relationship exists between dyslipidemia and increased non-invasive cSBP or whether these are components of a single disease or pathological state, like metabolic syndrome.

\section{Conclusions}

Increased blood RLP-C level was significantly associated with higher CSBP in a Chinese community-based population, independently of other lipid levels. These findings emphasize the importance of RLP-C in comprehensive individual cardiovascular risk assessment. Further studies should focus on determining causality and potential mechanisms in this relationship.

\section{Abbreviations}

CSBP: Central systolic blood pressure; TRLs: Triglyceride-rich lipoproteins;

TC: Total cholesterol; BMI: Body mass index; TG: Triglyceride; PWV: Pulse wave velocity; CAVI: Cardio-ankle vascular index; eGFR: Estimated glomerular filtration rate; IDL: Intermediate-density lipoprotein; VLDL: Very low-density 
lipoprotein; HDL-C: High-density lipoprotein cholesterol; DM: Diabetes mellitus; PWA: Pulse wave analysis; LDL-C: Low-density lipoprotein cholesterol; RLP-C: Remnant lipoprotein cholesterol; non-HDL-C: non-highdensity lipoprotein cholesterol; LDL: Low-density lipoprotein; Cl: confidence interval

\section{Acknowledgments}

We thank the entire study team for their participation and contributions. We also thank Kelly Zammit, BVSc, from Liwen Bianji (Edanz) (www.liwenbianji. $\mathrm{cn} /$ ), for editing the English text of a draft of this manuscript.

\section{Authors' contributions}

Y.Z. and J.Z. are responsible for the data resources and integrity. Y.Z., J.Z., B.Z. and Y.H. were in charge of the study concept and design. Y.Z., F.F., J.J., K.L., B.L., J.L. and C.C. conducted the entire study. F.F. and J.J. helped with data management and statistical analysis. K.L. analyzed the data and drafted the manuscript, and Y.Z., J.Z., Y.H., B.Z., F.F., J.J., B.L., J.L. and C.C. reviewed and revised the article. The authors read and approved the final manuscript.

\section{Funding}

University of Michigan Health Science -Peking University Health Science Centre (UMHS-PUHSC) Joint Institute for Translational and Clinical Research and the Fundamental Research Funds for the Central Universities (Grant No: BMU20110177 and BMU20160530); National Key Research and Development Project of China (Grant No. 2017YFC1307704); Key Laboratory of Molecular Cardiovascular Sciences (Peking University), Ministry of Education and National Health Commission Key Laboratory of Cardiovascular Molecular Biology and Regulatory Peptides; Chinese Cardiovascular Association- Access fund 2019-CCA-ACCESS-112.

\section{Availability of data and materials}

Data are available with reasonable request.

\section{Declarations}

\section{Ethics approval and consent to participate}

The study protocol was approved by Peking University First Hospital Ethics Committee, and all participants provided written informed consent. The study was performed in accordance with the principles of the Declaration of Helsinki.

\section{Consent for publication}

Not applicable.

\section{Competing interests}

None.

\section{Author details}

${ }^{1}$ Department of Cardiology, Peking University First Hospital, No. 8 Xishiku Street, Xicheng District, Beijing 100034, China. ${ }^{2}$ Institute of Cardiovascular Disease, Peking University First hospital, No. 8 Xishiku Street, Xicheng District, Beijing 100034, China.

\section{Received: 31 January 2021 Accepted: 14 June 2021}

Published online: 26 June 2021

\section{References}

1. Poulter NR, Prabhakaran D, Caulfield M. Hypertension. Hypertension Lancet. 2015;386(9995):801-12. https://doi.org/10.1016/S0140-6736(14)61468-9.

2. Roth GA, Mensah GA, Johnson CO, Addolorato G, Ammirati E, Baddour LM, et al. Global burden of cardiovascular diseases and risk factors, 1990-2019: update from the GBD 2019 study. J Am Coll Cardiol. 2020;76(25):2982-3021. https://doi.org/10.1016/j.jacc.2020.11.010.

3. Cheng HM, Chuang SY, Wang TD, Kario K, Buranakitjaroen P, Chia YC, et al. Central blood pressure for the management of hypertension: is it a practical clinical tool in current practice? J Clin Hypertens (Greenwich). 2020;22(3): 391-406. https://doi.org/10.1111/jch.13758.

4. Vlachopoulos C, Aznaouridis K, O'Rourke MF, Safar ME, Baou K, Stefanadis C. Prediction of cardiovascular events and all-cause mortality with central haemodynamics: a systematic review and meta-analysis. Eur Heart J. 2010; 31(15):1865-71. https://doi.org/10.1093/eurheartj/ehq024.
5. Wang KL, Cheng HM, Chuang SY, Spurgeon HA, Ting CT, Lakatta EG, et al. Central or peripheral systolic or pulse pressure: which best relates to target organs and future mortality? J Hypertens. 2009;27(3):461-7. https://doi.org/1 0.1097/HJH.0b013e3283220ea4.

6. Chi C, Yu X, Auckle R, Lu Y, Fan X, Yu S, et al. Hypertensive target organ damage is better associated with central than brachial blood pressure: the northern Shanghai study. J Clin Hypertens (Greenwich). 2017;19(12):126975. https://doi.org/10.1111/jch.13110.

7. Kollias A, Lagou S, Zeniodi ME, Boubouchairopoulou N, Stergiou GS. Association of Central Versus Brachial Blood Pressure with Target-Organ Damage: systematic review and meta-analysis. Hypertension. 2016;67(1): 183-90. https://doi.org/10.1161/HYPERTENSIONAHA.115.06066.

8. Wilkinson IB, Prasad K, Hall IR, Thomas A, MacCallum H, Webb DJ, et al. Increased central pulse pressure and augmentation index in subjects with hypercholesterolemia. J Am Coll Cardiol. 2002;39(6):1005-11. https://doi. org/10.1016/S0735-1097(02)01723-0.

9. Ferrara LA, Guida L, lannuzzi R, Celentano A, Lionello F. Serum cholesterol affects blood pressure regulation. J Hum Hypertens. 2002;16(5):337-43. https://doi.org/10.1038/sj.jhh.1001388.

10. Mancia G, Facchetti R, Bombelli M, Polo Friz H, Grassi G, Giannattasio C, et al. Relationship of office, home, and ambulatory blood pressure to blood glucose and lipid variables in the PAMELA population. Hypertension. 2005; 45(6):1072-7. https://doi.org/10.1161/01.HYP.0000165672.69176.ed.

11. Yan Z, Bi-Rong D, Hui W, Chang-Quan H. Serum lipid/lipoprotein and arterial blood pressure among Chinese nonagenarians/centenarians. Blood Press. 2011;20(5):296-302. https://doi.org/10.3109/08037051.2011.572590.

12. Castaner O, Pinto X, Subirana I, Amor AJ, Ros E, Hernaez A, et al. Remnant cholesterol, not LDL cholesterol, is associated with incident cardiovascular disease. J Am Coll Cardiol. 2020;76(23):2712-24. https://doi.org/10.1016/j.ja cc.2020.10.008.

13. Joshi PH, Khokhar AA, Massaro JM, Lirette ST, Griswold ME, Martin SS, et al. Remnant Lipoprotein Cholesterol and Incident Coronary Heart Disease: The Jackson Heart and Framingham Offspring Cohort Studies. J Am Heart Assoc. 2016;5(5). https://doi.org/10.1161/JAHA.115.002765.

14. Chapman MJ, Ginsberg HN, Amarenco P, Andreotti F, Boren J, Catapano AL, et al. Triglyceride-rich lipoproteins and high-density lipoprotein cholesterol in patients at high risk of cardiovascular disease: evidence and guidance for management. Eur Heart J. 2011;32(11):1345-61. https://doi.org/10.1093/ eurheartj/ehr112.

15. Kasahara A, Adachi H, Hirai Y, Enomoto M, Fukami A, Yoshikawa K, et al. High level of plasma remnant-like particle cholesterol may predispose to development of hypertension in normotensive subjects. Am J Hypertens. 2013;26(6):793-8. https://doi.org/10.1093/ajh/hpt011.

16. Fan F, Qi L, Jia J, Xu X, Liu Y, Yang Y, et al. Noninvasive central systolic blood pressure is more strongly related to kidney function decline than peripheral systolic blood pressure in a Chinese community-based population. Hypertension. 2016;67(6):1166-72. https://doi.org/10.1161/ HYPERTENSIONAHA.115.07019.

17. Momin M, Fan F, Li J, Qin X, Jia J, Qi L, et al. Associations of plasma homocysteine levels with peripheral systolic blood pressure and noninvasive central systolic blood pressure in a community-based Chinese population. Sci Rep. 2017;7(1):6316. https://doi.org/10.1038/s41598-017-06611-3.

18. Fan F, Jia J, Li J, Huo Y, Zhang Y. White blood cell count predicts the odds of kidney function decline in a Chinese community-based population. BMC Nephrol. 2017;18(1):190. https://doi.org/10.1186/s12882-017-0608-4.

19. Wang S, Zhou Z, Fan F, Qi L, Jia J, Sun P, et al. Joint effect of non-invasive central systolic blood pressure and peripheral systolic blood pressure on incident hypertension in a Chinese community-based population. Sci Rep. 2018;8(1):3229. https://doi.org/10.1038/s41598-018-21023-7.

20. Takazawa K, Kobayashi H, Kojima I, Aizawa A, Kinoh M, Sugo Y, et al. Estimation of central aortic systolic pressure using late systolic inflection of radial artery pulse and its application to vasodilator therapy. J Hypertens. 2012;30(5):908-16. https://doi.org/10.1097/HJH.0b013e3283524910.

21. Takazawa K, Kobayashi H, Shindo N, Tanaka N, Yamashina A. Relationship between radial and central arterial pulse wave and evaluation of central aortic pressure using the radial arterial pulse wave. Hypertens Res. 2007; 30(3):219-28. https://doi.org/10.1291/hypres.30.219.

22. Ding FH, Fan WX, Zhang RY, Zhang Q, Li Y, Wang JG. Validation of the noninvasive assessment of central blood pressure by the SphygmoCor and Omron devices against the invasive catheter measurement. Am J Hypertens. 2011;24(12):1306-11. https://doi.org/10.1038/ajh.2011.145. 
23. Wohlfahrt P, Krajcoviechova A, Seidlerova J, Mayer O, Filipovsky J, Cifkova R. Comparison of noninvasive assessments of central blood pressure using general transfer function and late systolic shoulder of the radial pressure wave. Am J Hypertens. 2014;27(2):162-8. https://doi.org/10.1093/ajh/hpt166.

24. Kips JG, Schutte AE, Vermeersch SJ, Huisman HW, Van Rooyen JM, Glyn MC, et al. Comparison of central pressure estimates obtained from SphygmoCor, Omron HEM-9000Al and carotid applanation tonometry. J Hypertens. 2011; 29(6):1115-20. https://doi.org/10.1097/HJH.0b013e328346a3bc.

25. Yeom H, Kim HC, Lee JM, Jeon Y, Suh I. Triglyceride to high density lipoprotein cholesterol ratio among adolescents is associated with adult hypertension: the Kangwha study. Lipids Health Dis. 2018;17(1):212. https:// doi.org/10.1186/s12944-018-0861-y.

26. Adank MC, Benschop L, Peterbroers KR, Smak Gregoor AM, Kors AW, Mulder $M T$, et al. Is maternal lipid profile in early pregnancy associated with pregnancy complications and blood pressure in pregnancy and long term postpartum? Am J Obstet Gynecol. 2019;221(2):150 e1- e13.

27. Stancu CS, Toma L, Sima AV. Dual role of lipoproteins in endothelial cell dysfunction in atherosclerosis. Cell Tissue Res. 2012;349(2):433-46. https:// doi.org/10.1007/s00441-012-1437-1.

28. Zheng XY, Liu L. Remnant-like lipoprotein particles impair endothelial function: direct and indirect effects on nitric oxide synthase. J Lipid Res. 2007;48(8):1673-80. https://doi.org/10.1194/jlr.R700001-JLR200.

29. Doi H, Kugiyama K, Oka H, Sugiyama S, Ogata N, Koide SI, et al. Remnant lipoproteins induce proatherothrombogenic molecules in endothelial cells through a redox-sensitive mechanism. Circulation. 2000;102(6):670-6. https://doi.org/10.1161/01.CIR.102.6.670.

30. Borghi C, Urso R, Cicero AF. Renin-angiotensin system at the crossroad of hypertension and hypercholesterolemia. Nutr Metab Cardiovasc Dis. 2017; 27(2):115-20. https://doi.org/10.1016/j.numecd.2016.07.013.

31. Kurtel H, Rodrigues SF, Yilmaz CE, Yildirim A, Granger DN. Impaired vasomotor function induced by the combination of hypertension and hypercholesterolemia. J Am Soc Hypertens. 2013;7(1):14-23. https://doi. org/10.1016/j.jash.2012.11.005.

32. Sposito AC. Emerging insights into hypertension and dyslipidaemia synergies. Eur Heart J Suppl. 2004;6(7):G8-G12. https://doi.org/10.1016/j. ehjsup.2004.10.003.

33. Ivanovic B, Tadic M. Hypercholesterolemia and hypertension: two sides of the same coin. Am J Cardiovasc Drugs. 2015;15(6):403-14. https://doi.org/1 0.1007/s40256-015-0128-1.

34. Kabutoya T, Kario K. Comparative assessment of cutoffs for the cardio-ankle vascular index and brachial-ankle pulse wave velocity in a Nationwide registry: a cardiovascular prognostic coupling study. Pulse (Basel). 2019;6(34):131-6. https://doi.org/10.1159/000489604.

35. Salvi P, Scalise F, Rovina M, Moretti F, Salvi L, Grillo A, et al. Noninvasive estimation of aortic stiffness through different approaches. Hypertension. 2019;74(1):117-29. https://doi.org/10.1161/HYPERTENSIONAHA.119.12853.

36. Namba T, Masaki N, Takase B, Adachi T. Arterial Stiffness Assessed by CardioAnkle Vascular Index. Int J Mol Sci. 2019;20(15). https://doi.org/10.3390/ijms2 0153664.

37. Pavlovska I, Kunzova S, Jakubik J, Hruskova J, Skladana M, Rivas-Serna IM, et al. Associations between high triglycerides and arterial stiffness in a population-based sample: Kardiovize Brno 2030 study. Lipids Health Dis. 2020;19(1):170. https://doi.org/10.1186/s12944-020-01345-0.

38. Zhan B, Huang X, Wang J, Qin X, Zhang J, Cao J, et al. Association between lipid profiles and arterial stiffness in Chinese patients with hypertension: insights from the CSPPT. Angiology. 2019;70(6):515-22. https://doi.org/10.11 77/0003319718823341.

39. Gottsater M, Ostling G, Persson M, Engstrom G, Melander O, Nilsson PM. Non-hemodynamic predictors of arterial stiffness after 17 years of follow-up: the Malmo diet and Cancer study. J Hypertens. 2015;33(5):957-65. https:// doi.org/10.1097/HJH.0000000000000520.

40. Wang F, Ye P, Luo L, Xiao W, Qi L, Bian S, et al. Association of serum lipids with arterial stiffness in a population-based study in Beijing. Eur J Clin Investig. 2011:41(9):929-36. https://doi.org/10.1111/j.1365-2362.2011.02481.x.

41. White DA, Anand GM, Qayum O, Ibezim CF, Sherman AK, Raghuveer G. Modifiable clinical correlates of vascular health in children and adolescents with dyslipidemia. Pediatr Cardiol. 2019;40(4):805-12. https://doi.org/10.1 007/s00246-019-02071-w.

42. Wang L, Zhi F, Gao B, Ni J, Liu Y, Mo X, et al. Association between lipid profiles and arterial stiffness: a secondary analysis based on a cross-sectional study. J Int Med Res. 2020;48(7):300060520938188. https://doi.org/10.1177/0300060520938188.
43. Ferrier KE, Muhlmann MH, Baguet JP, Cameron JD, Jennings GL, Dart AM, et al. Intensive cholesterol reduction lowers blood pressure and large artery stiffness in isolated systolic hypertension. J Am Coll Cardiol. 2002;39(6): 1020-5. https://doi.org/10.1016/S0735-1097(02)01717-5.

44. Sahebkar A, Pecin I, Tedeschi-Reiner E, Derosa G, Maffioli P, Reiner Z. Effects of statin therapy on augmentation index as a measure of arterial stiffness: a systematic review and meta-analysis. Int J Cardiol. 2016;212:160-8. https:// doi.org/10.1016/j.ijcard.2016.03.010.

45. Townsend RR, Rosendorff C, Nichols WW, Edwards DG, Chirinos JA, Fernhall $B$, et al. American Society of Hypertension position paper: central blood pressure waveforms in health and disease. J Am Soc Hypertens. 2016;10(1): 22-33. https://doi.org/10.1016/j.jash.2015.10.012.

46. Choudhary MK, Eraranta A, Tikkakoski AJ, Koskela J, Hautaniemi EJ, Kahonen $\mathrm{M}$, et al. LDL cholesterol is associated with systemic vascular resistance and wave reflection in subjects naive to cardiovascular drugs. Blood Press. 2019; 28(1):4-14. https://doi.org/10.1080/08037051.2018.1521263.

47. Sandesara PB, Virani SS, Fazio S, Shapiro MD. The forgotten lipids: triglycerides, remnant cholesterol, and atherosclerotic cardiovascular disease risk. Endocr Rev. 2019;40(2):537-57. https://doi.org/10.1210/er.2018-00184.

48. Salinas CAA, Chapman MJ. Remnant lipoproteins: are they equal to or more atherogenic than LDL? Curr Opin Lipidol. 2020;31(3):132-9. https://doi.org/1 0.1097/MOL.0000000000000682.

49. Varbo A, Nordestgaard BG. Remnant lipoproteins. Curr Opin Lipidol. 2017; 28(4):300-7. https://doi.org/10.1097/MOL.0000000000000429.

50. Saeed A, Feofanova EV, Yu B, Sun W, Virani SS, Nambi V, et al. Remnant-like particle cholesterol, low-density lipoprotein triglycerides, and incident cardiovascular disease. J Am Coll Cardiol. 2018;72(2):156-69. https://doi. org/10.1016/j.jacc.2018.04.050.

51. Vallejo-Vaz AJ, Fayyad R, Boekholdt SM, Hovingh GK, Kastelein JJ, Melamed $\mathrm{S}$, et al. Triglyceride-rich lipoprotein cholesterol and risk of cardiovascular events among patients receiving statin therapy in the TNT trial. Circulation. 2018;138(8):770-81. https://doi.org/10.1161/CIRCULATIONAHA.117.032318.

52. Varbo A, Benn M, Nordestgaard BG. Remnant cholesterol as a cause of ischemic heart disease: evidence, definition, measurement, atherogenicity, high risk patients, and present and future treatment. Pharmacol Ther. 2014; 141(3):358-67. https://doi.org/10.1016/j.pharmthera.2013.11.008.

53. Hartz J, Krauss RM, Gottsater M, Melander O, Nilsson P, Mietus-Snyder M. Lipoprotein particle predictors of arterial stiffness after 17 years of follow up: the Malmo diet and Cancer study. Int J Vasc Med. 2020;2020:4219180.

54. Boren J, Chapman MJ, Krauss RM, Packard CJ, Bentzon JF, Binder CJ, et al. Low-density lipoproteins cause atherosclerotic cardiovascular disease: pathophysiological, genetic, and therapeutic insights: a consensus statement from the European atherosclerosis society consensus panel. Eur Heart J. 2020;41(24):2313-30. https://doi.org/10.1093/eurheartj/ehz962.

55. Taguchi M, Ishigami M, Nishida M, Moriyama T, Yamashita S, Yamamura T. Remnant lipoprotein-cholesterol is a predictive biomarker for large artery atherosclerosis in apparently healthy women: usefulness as a parameter for annual health examinations. Ann Clin Biochem. 2011;48(Pt 4):332-7. https:// doi.org/10.1258/acb.2011.010244.

56. Balling M, Afzal S, Varbo A, Langsted A, Davey Smith G, Nordestgaard BG. VLDL cholesterol accounts for one-half of the risk of myocardial infarction associated with apoB-containing lipoproteins. J Am Coll Cardiol. 2020;76(23): 2725-35. https://doi.org/10.1016/j.jacc.2020.09.610.

57. Strazzullo P, Kerry SM, Barbato A, Versiero M, D'Elia L, Cappuccio FP. Do statins reduce blood pressure?: a meta-analysis of randomized, controlled trials. Hypertension. 2007:49(4):792-8. https://doi.org/10.1161/01.HYP.00002 59737.43916.42

58. Golomb BA, Dimsdale JE, White HL, Ritchie JB, Criqui MH. Reduction in blood pressure with statins: results from the UCSD statin study, a randomized trial. Arch Intern Med. 2008;168(7):721-7. https://doi.org/10.1 001/archinte.168.7.721

59. Kanaki Al, Sarafidis PA, Georgianos PI, Kanavos K, Tziolas IM, Zebekakis PE, et al. Effects of low-dose atorvastatin on arterial stiffness and central aortic pressure augmentation in patients with hypertension and hypercholesterolemia. Am J Hypertens. 2013;26(5):608-16. https://doi.org/1 0.1093/ajh/hps098.

60. Williams B, Lacy PS, Cruickshank JK, Collier D, Hughes AD, Stanton A, et al. Impact of statin therapy on central aortic pressures and hemodynamics: principal results of the conduit artery function evaluation-lipid-lowering arm (CAFE-LLA) study. Circulation. 2009;119(1):53-61. https://doi.org/10.1161/ CIRCULATIONAHA.108.785915. 
61. Spannella F, Giulietti F, Di Pentima C, Sarzani R. Prevalence and control of dyslipidemia in patients referred for high blood pressure: the disregarded "double-trouble" lipid profile in overweight/obese. Adv Ther. 2019;36(6): 1426-37. https://doi.org/10.1007/s12325-019-00941-6.

62. Spannella F, Filipponi A, Giulietti F, Di Pentima C, Bordoni V, Sarzani R. Statin therapy is associated with better ambulatory blood pressure control: a propensity score analysis. J Hypertens. 2020;38(3):546-52. https://doi.org/1 0.1097/HJH.0000000000002276.

63. Lamarche F, Agharazii M, Nadeau-Fredette AC, Madore F, Goupil R. Central and brachial blood pressures, statins, and low-density lipoprotein cholesterol: a mediation analysis. Hypertension. 2018;71(3):415-21. https:// doi.org/10.1161/HYPERTENSIONAHA.117.10476.

\section{Publisher's Note}

Springer Nature remains neutral with regard to jurisdictional claims in published maps and institutional affiliations.

Ready to submit your research? Choose BMC and benefit from:

- fast, convenient online submission

- thorough peer review by experienced researchers in your field

- rapid publication on acceptance

- support for research data, including large and complex data types

- gold Open Access which fosters wider collaboration and increased citations

- maximum visibility for your research: over $100 \mathrm{M}$ website views per year

At BMC, research is always in progress.

Learn more biomedcentral.com/submissions 